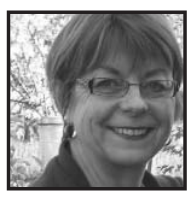

\title{
Learning to Lead: Lessons From the Field
}

\author{
Julie Hobbs, Education Consultant
}

\begin{abstract}
In this article, the author recalls experiences from her career, and shares them as five lessons learned about leadership. She explains that a mentoring culture did not exist for her or others when she assumed various leadership roles in her school board, and she argues that possibilities exist for a strong mentoring culture now. The five lessons presented focus on caring and compassion, trust and risk-taking, listening, collaboration and shared governance, and facilitating and mentoring.
\end{abstract}

\section{Introduction}

t the age of 24 , I was named head teacher of a high school for students with special needs. At that time, I had a quote posted on my office wall which read, "Lead, Follow, or Get Out of the Way!" (Paine, 1776). It took me the next 34 years to learn that there was a whole lot more to leadership than those eight words. As we move through the early years of the $21^{\text {st }}$ century, I continue to learn what defines successful leadership in education. It is constantly readjusted by an evolving curriculum and culture, rethought and reworked to better address the needs of a changing society and to prepare students to take their place in a shrinking global community.

My career began in a small high school on the South Shore of Montreal. As a new teacher, with a background in Anthropology and trained to teach History and Geography in high schools, I barely knew what special education was. I remember at my job interview, when asked if I would teach special education, saying, "Sure, what's that?" I would soon find out. 
As I looked for the answers to address the needs of my students, little did I know that this field of special education would shape my career. In my years with the school board, I taught special education as a classroom teacher and after two years, became the school's head teacher. My search for answers on how to teach reading to my special education students sent me back to university for a Master's Degree in Education. I was later a reading specialist and special education consultant with the school board and a school administrator-both in a special education school and a primary elementary school. In my final 12 years with the school board, I was the Director of Instructional Services and then Assistant Director General, responsible for Curriculum and Complementary Services. It is through this sequence of experiences that I came to understand that the role of leadership in an organization requires caring first about the people as they work through change within an organization, along with the well-being and future direction of the organization. Robert Greenleaf (1977) suggests, in his discussions on servant leadership (leaders who serve first and encourage relational interactions and the ethical use of power), that the problem with big institutions is that they do not serve well. He quotes a former professor of his as saying, " ... nothing of substance will happen unless there are people inside these institutions who are able to (and want to) lead them into better performance for the public good. Some of you ought to make careers inside these big institutions and become a force for good - from the inside" (p. 3).

When I was named head teacher, there was little support for the development of leadership skills or the nurturing of new leaders. Our philosophy and our direction were formed by our experiences in the field. In fact, in those years, very few educators came to leadership roles by design or with much preparation. More than once, I found myself sitting alone at a desk in an office, wondering what to do next and hoping that there would be someone who would walk through the door and have the answer. How different our experiences might have been had we had the advantage of a coach or a mentor in our early years. Zachary (2005) suggests that, "Creating a mentoring culture is a journey of organizational learning in which mentoring competency and mastery are enhanced at all levels: participant, leadership, administrative and institutional" (2005, p. xxiii). In my early experiences, it was often the school secretary who provided the guidance to get us through our first few months and days and showed us the way.

As educators, we came to leadership positions by chance in many cases. At a point in time, we had demonstrated some ability to lead, to take charge, to organize a major school event or curriculum project or take up a role because no one else was coming forward to do it. We had shown the right leadership traits, at a moment in time, when there was a need for someone to take responsibility for a particular job 
or action. Suddenly we found ourselves, for example, as a head teacher of a school for special needs or as a principal of an elementary school or as the director of instructional services in a school board. Our leadership training began on the job and developed as we faced each new challenge. Our leadership skills evolved by happenstance related to the circumstances in which we found ourselves at the time. Each lesson was a building block for the next and the lesson learned became a part of the fabric of who we are, as we struggled and worked to understand the needs and demands that were set before us. If we were lucky, we possessed intuitively some of the five components that Fullan (2002) suggests are essential characteristics of educational leaders: moral purpose, an understanding of the change process, the ability to improve relationships, knowledge creation and sharing and coherence making. I think what components came most easily to us were moral purpose and relationship development. We wanted to make a difference in the lives of our students and we, perhaps only intuitively, knew that we needed to build relationships with our students if we were to have any impact. It was only later that we learned about emotional intelligence and how essential it is for making change in any organization. Goleman (2008) argues that "outstanding leadership requires a combination of self-mastery and social intelligence .... When it comes to leaders, effectiveness in relationships makes or breaks. Solo stars are often promoted to leadership positions and then flounder for lack of people skills" (p. 1). The question is what moved us as young, inexperienced leaders to understand that building relationships with our students and colleagues was crucial for our teaching and working with them. The following stories exemplify the impact of emotional intelligence in moving an organization forward through change.

\section{Lesson 1 - Caring and Compassion}

As mentioned earlier my leadership learning began at that small secondary school designated for special students. It had a student body of 108 special needs students and a staff of 9 teachers. Six of us had never taught before our assignment there. In my third year at the school, I became head teacher in the school by default, after a long search for an experienced male administrator willing to take on the assignment-it was 1973, after all. There were none, and I was given the job. My lessons came fast and furiously.

All of the students had been placed in the school because they did not "fit" into a regular high school program. Many of the students came from impossible home situations. Some came with severe mental health problems. This was the first 
educational placement that they had had following a long-term hospitalization in a psychiatric ward. At the beginning, daily crises were the rule of the school, as students clashed with each other and with us, over any request or instruction they received. They behaved outrageously and we had very little experience in coping with the extreme behaviours that faced us on a daily basis. Classroom management, not instruction, became our immediate focus. We worked hard at trying to connect with our students. They worked equally hard at taking their place and gaining the attention of others in any way that they could. They were students who had failed in the regular school system and were removed from the general population to be placed in a special school, and they resented it far more than we realized. This point was driven home to me by one of my students, when we were on an overnight field trip. While she was a very difficult student in the school, she was particularly well behaved on this trip. At one point, I asked her, "Why is your behaviour so different here from what it is at school?" Without even thinking, she said, "The school is a mental school, we're supposed to act mental there." It was a turning point in my thinking-we had been treating our students as special needs students, instead of thinking of them as students with needs. We were dealing with their individual behaviours and forgetting to look at the students as needy children first. Their needs, we were learning were far greater than academic achievement. Dewey (1998) talks about placing a strong emphasis on the subjective quality of a student's experience and the necessity for the teacher to understand the past experiences in order to effectively design a sequence of liberating educational experiences to allow the person to fulfill his or her potential as a member of society. From our students we learned that their pasts had been traumatic and that many lived in marginal situations on a daily basis. To many school was their haven for a few hours a day.

Heller (2002) talks of the power of gentleness in education, that kindness and compassion are rarely mentioned in seminars and presentations on educational leadership. Education, he contends, is not about production models, power models or business models, but about service. "And service entails listening to others, caring for them and quietly going about doing your job" ( p. 76).

These students taught me that no matter what their challenges were, they were people first-with fears and issues like any other student. They needed to be listened to and we needed to care for them. Interestingly enough, we did not know the theoretical basis for our actions at the time, but today we know that the development of a relationship with a student is one of the most powerful educational building blocks (Fullan, 2002; Goleman, 2008). Heller (2002) argues that, “Education should be about helping students become humane, caring individuals, capable of dealing 
with complex issues that the world presents. We can model humane behaviour for our students without sacrificing standards of learning or behaviour" (p. 77).

Nothing can be more relevant to students than trying to help them sort out a conflictual situation with their parents, with their peers or even as I discovered, with their drug dealer when money was owed. I recall feeling way beyond my range of skills when I tried to help a 14 year-old boy address how he was going to survive the next visit from his drug dealer: laying out the situation with him-deciding on the possible courses of action. What were the possibilities that he had not thought of yet? What seemed to make the most sense? How might he avoid finding himself in this situation again? We never really knew how many of these situations ended at the time, but as educators, we took the time it needed to show them that we cared what happened to them, and that we wanted them to be safe.

Did our interventions as their teachers shape their lives? Did they learn caring and compassion from us? Our only evidence is that we have the advantage of seeing our students as adults today, now in their 40s and 50s. They contact some of us every so often. The proof of our impact is in what we observe 30 years later. For the most part, we see many of our former students as successful adults. They have families and they have maintained jobs, some for over 20 years.

\section{Lesson 2-Trust and Risk Taking}

Several years later, I began to work more closely with teachers as a pedagogical consultant. My role was to help teachers diversify their teaching and to take on new practices that would address the needs of a wide range of students in a classroom. A wise university professor had once told me that it was most important for us as instructional leaders to have a solid working relationship with staff, so that when they were asked to do tasks which seemed impossible to them, they would do it because they trusted us. It was advice that I have relied on over and over again in the various roles I have played. It is supported by Hargreaves and Fink (2006) who described trust, confidence and emotion, as sources of human resourcefulness that drive the power of renewal in change."Trust is an indispensable resource for improvement" (p. 212) with "positive organizational consequences in terms of 'more effective decision-making, enhanced social support for innovation' ..." (p. 214).

This lesson was well illustrated when I asked a teacher to provide writing opportunities for her young students in authentic learning situations, for example, to 
begin having her kindergarten children keep a journal of their daily activities. "But they can't write," she said. We talked about having them express their ideas orally and drawing a picture and then writing what they could to describe their experiences. Reluctantly, she agreed.

Three months later, she brought me samples of work from a student who had special needs. This student had moved from scribbling to forming some sequences of letters, to writing legible three to four word sentences about her daily activities. The teacher was convinced and the students were writing. Sometimes it takes a giant leap of faith—or a trusting relationship_-for innovation to take a foothold.

This experience taught me much about the importance of building trust with our staff before launching our "off-the-wall" ideas and initiatives. It also showed me the capacity for risk taking that educators have if they believe in and trust the person with whom they are working and if this accompanies an issue or concern that requires further thought and investigation.

\section{Lesson 3-Listening}

Initiating and managing change in a school have become central to an administrator's role over the last ten years. Sustaining that change is a complex task that initially is not easily understood. I clearly did not understand this complexity in the early 90s, when I became a principal of a small elementary school with a culturally diverse, population of students. I did understand that there needed to be goals and direction for the school to be successful. An enriched curriculum embedded in a school-wide theme and a focus on literacy in an inclusive setting which accepted all children into this school community seemed good ways to attract families to this school with a strong English program. It did not seem like a far stretch for this little school with 200 students since the staff had earlier embarked on a strong schoolwide literacy program.

While the staff, students and parents were enthusiastic about many of the ideas, they viewed these suggestions as discrete projects and activities and not as part of a bigger plan to move the culture of the school to a richer, more stimulating environment for all students and staff. Fullan (2002), in his examination of "The Change Leader," reminds us that "The goal is not to innovate the most. Innovating selectively with coherence is better" (p. 17). While I thought that I had shared my vision of enrichment with all its complexity with the whole staff, I had not waited to 
see if members of the staff accepted this direction as their own and were ready to pursue the changes we had discussed.

It was not long before one of the teachers was assigned the task of coming to speak to me, to let me know that the staff was upset and that the changes were too rapid. "You are moving too fast," she ventured. "The teachers are not behind you and you are going to lose them." The teachers were overwhelmed and were stressed by the rate of change. The staffroom talk was reaching a point of high stress and disgruntlement. Despite being deflated with this reaction, I thanked that teacher for coming forward, and we talked about ways that teachers could become less stressed. We began with a staff meeting where I spoke to the teachers about what my aims were. I indicated that I understood their concerns and acknowledged that I had made a mistake in trying to move too quickly. Based on our desire for improvement we brainstormed a direction for the school to readjust our course, and worked through possible next steps.

Had I known at the time about Fullan's (2002) five essential components characterizing leaders in a knowledge society, would the crisis have been averted? I am not sure. Perhaps I would have understood more; perhaps I would have checked to make sure that the teachers were supporting and supported in the next steps. Fullan contends that while principals are

...not attuned to leading in a culture of change make the mistake of seeking external innovations and taking on too many projects .... Culture Change Principals ... realize that overload and fragmentation are natural tendencies of complex systems. They appreciate the creative potential of diverse ideas, but strive to focus energy and achieve greater alignment .... [they] value the tensions inherent in addressing hard-to-solve problems because that is where the greatest accomplishments lie. (pp.18-19)

In our school, some teachers had recognized the tensions and one brave soul came forward to speak about them.

There is a fine balance between creating the desire and capacity for change and developing a sustainable growth rate. "Like cross-country skiing, school improvement needs the right amount of energy at the right time" (Hargreaves, 2007, p. 21). Hearing from the teachers was a crucial part of the process. Their participation in adjusting our goals and directions was essential. Working through the dissention with the staff helped to move the process forward. Had I opted to ignore their concerns, it would have been impossible to move forward. Listening to where the staff was helped lead the process of change forward. 


\section{Lesson 4-Collaboration and Shared Governance}

In the past few years in Quebec, there have been many challenges in leading organizations through change. The reorganization of school boards, changes to the Education Act and the Basic School Regulations, and the introduction of a new Quebec Education Program have all stretched educators' capacity to manage change. The greatest fundamental change to the way in which school leaders have functioned has been the introduction of shared governance of schools with other partners-parents, staff members, and community partners. These partners participate in the decision making that determines the direction of the school, the educational project and the school success plans. Shared governance and the participation of the stakeholders are essential in the response of a healthy organization to its constituents. However, there is not much that has prepared educational leaders to share authority and to facilitate the building of consensus. Learning to collaborate and build consensus within a group is a lesson learned at the grassroots as partners are brought together to develop an organizational direction and work through complex relationships and the development of a common vision and goals.

Hargreaves and Fink (2006) address shared governance in their work on "leadership" and caution that

...if [groups] are not bound together by a clear vision, tight processes and clear accountability, multiple sources of leadership can pull a school apart. The consequences of not distributing leadership are staleness and stagnation. The risks of distributing leadership are anarchy and confusion. (pp. 111-112)

One of the essential prerequisites of working collaboratively to establish the common vision is the capacity to respect diversity and to understand that there are differences in perspectives. My background in anthropology has probably been one of my most useful assets in learning to respect different cultural values and views of the world. It is not as simple as it sounds to be able to put yourself in another person's shoes, but it is an invaluable asset when trying to connect with a diverse group of people who have different interests and different perspectives.

Developing common goals and direction is often done through committee work. Frequently, people find the process to be inefficient and very frustrating. Learning to constructively participate in a productive meeting is clearly a blending of art and science while building a common vision and direction. As a director of serv- 
ice in a school board, I sat on as many as 18 committees a year and chaired as many as eight different groups both internal and external to the school board. It seemed most of my daytime and evening hours were spent in committees working through the process of building consensus and direction in order to improve policies and directions for the organization and ultimately for the students and employees it served.

A camel is a horse designed by a committee. This is a phrase often used to underline the awkwardness and frustration of committee discussions and decisions. It is only through meeting and discussion, however, that one can build the dynamics of the group and the working relationships which lead, more often than not, to respect and trust of the individuals around the table. It is important to anticipate and respect other members' points of view; to work to identify the common interests, establish common ground and clear goals, and to set a direction and reach a consensus for action with a follow-up plan. I learned most from my work with the teachers' union on parity committees, where the administrators and teacher representatives sat in equal numbers. Initially these committees were probably the hardest to make things move along productively, because of differing points of view. Yet they were often the most productive when we could agree on a common vision and a common goal and build that together into a policy or procedure that provided direction for working with our students. I appreciated the point of view of the teachers. While our committee meetings were loud and often off topic, they were good examples of how differing viewpoints could be worked into an acceptable direction. Designing by committee continues to be a lesson in lifelong learning, and an essential one, especially when used judiciously, particularly as leaders prepare their students for a global stage which will rely on their skills of collaboration and negotiation much beyond our current understanding.

\section{Lesson 5-Facilitating and Mentoring}

In the last years of service within an organization, developing a strong team to take the leadership after one leaves is crucial for the well-being of the organization and for the continuity of services provided to students, staff and parents. It is probably the best opportunity that one has to be able to pull together all the lessons learned and to begin to share those lessons with others, while encouraging them to assume more and more complex leadership roles in the process. 
In the last years of my career, I worked with a phenomenal group of administrators, professionals and support staff who provided the schools in our school board with educational services-both curriculum and complementary services. Most of my time, apart from sitting on those committees described above, was spent talking with the coordinators and professionals who worked every day in our schools, with greater or lesser success, given the task before them and the receptiveness of the staff they were supporting. Debriefing, analyzing difficult situations, coming up with potential directions, trying them out, and debriefing again ... was our pattern of conversation.

Frequently, on a Thursday or Friday afternoon, after everyone else had left the office for the weekend, a small group of us could be found standing together and reviewing the events of the week or the crisis of the day, and trying to figure out the next best steps. It was frequently the only time the consultants saw me or each other in a week, as they spent most of their time in schools. Our impromptu "corridor" meetings were a variation on Tom Peters' (1985) notion of "management by wandering around" (p. 402) and became a regular means of keeping in touch with each other.

It became clear to me that my most important role as their director, apart from establishing a common direction and goals for the department, was to facilitate their self-awareness, encourage them, help them keep sight of the big picture, to anticipate the bumps in the road, to celebrate their successes and to provide some opportunity for reflection and consolation during their more difficult times. In essence, my role was to transfer the skills, perceptions and leadership capacity that I had learned and internalized through my years in the field. It was an important step in preparing them for change as they would lead the curriculum changes with those who were taking my place.

As I approached retirement, I looked forward to a shift in the intensity of my work life-that is, shorter than 60-hour workweeks, daily schedules that are my own design, and time for myself. Yet I knew that I had a lot that I wanted to give back and contribute. We, the baby boomers, are now the new elders. Our greatest challenge becomes working out the balance of giving back and both "savouring and saving the world" (Schimke, 2007, p. 37). Our obligation is to help build a new generation of educational leaders and see them through these times of considerable change. How can they benefit from some of our experiences and lessons we learned "by the seat of our pants"? We have a significant potential for assisting our younger and less experienced colleagues through their early years. We can help them through some of the challenges that we as educational leaders faced entirely on our own. Perhaps with our 
support, through a culture of mentoring, our young leaders will be able to benefit from their experiences in the context of a learning environment.

As retired leaders, we "get to step back from the hectic day-to-day routines and broaden [our] scope" (Varlas, 2007, p. 8). In roles as leadership coaches and mentors, we can become valued as teachers of young educators and feel that our ideas and experiences might make a difference in their learning.

\section{Conclusion}

As many of us who have been active in school boards reach retirement, we will be looking to what our new challenges will be, where our new "buzz" will come from. Many of us - the boomers - will be outside the formal organizational structure, perhaps looking to "retread" more than retire. As we leave our organizations, we will take with us the history, the culture and a certain level of experience and expertise. Through my 34 years of experience, I have come to understand the need to build strong relationships - with students, with teachers, with administrators, with professionals and with parents. I know that it is essential to develop the "people skills," that social intelligence is really the heart of an organization. To build trust and encourage risk taking (albeit, sometimes, in small steps) is crucial for leading change in an educational organization. To build collaborative models that have a focus on vision, goals, process and accountability, in a spirit of caring, is what we all strive for in our work. This understanding is important for the strength and continuity of an organization.

Taschereau and Bolger (2007) identify leadership characteristics that will serve the leaders of the $21^{\text {st }}$ century as new organizational structures are explored and developed. I understand now that leadership is not simply a choice of leading, following or getting out of the way. It is working within multiple communities to network, vision, create, design and build an education for and with our students who will be adults in a world we can only begin to imagine. This is what leadership is all about. 


\section{References}

Dewey, J. (1998). Experience and Education: Sixtieth Anniversary Edition. West Lafayette, Indiana: Kappa Delta Pi.

Fullan, M. (2002). The Change Leader. Educational Leadership: Beyond Instructional Leadership. 59(8), 16-20.

Glanz, J. (2002). Finding Your Leadership Style: A Guide for Educators. Alexandria, VA: ASCD.

Goldberg, M. (2001). Lessons from Exceptional School Leaders. Alexandria, VA: ASCD.

Goleman, D. (2008). Leadership: Social Intelligence Is Essential. Retrieved April 22, 2008, from http://www.danielgoleman. info/blog/2008/02/28/leadership-socialintelligence-is-essential

Greenleaf, R. (1977). Servant Leadership: A Journey into the Nature of Legitimate Power and Greatness. New York: Paulist Press.

Hargreaves, A. (2007). The Long and Short of Educational Change. Education Canada, Summer, 2007, 16-23.

Hargreaves, A. \& Fink, D. (2006). Sustainable Leadership. San Francisco: Jossey-Bass.
Heller, D. (2002). The Power of Gentleness. Educational Leadership: Beyond Instructional Leadership, 59(8), 76-79.

Paine, T. (1776). Retrieved June 10, 2008, from www.quotedb.com/quotes/1738

Peters, T \& Austin, N. (1985). A Passion for Excellence: The Leadership Difference. New York: Random House.

Schimke, D. (2007). The New Elders. Utne Reader, October 2007, 34-38.

Taschereau, S. \& Bolger, J. (2007). Networks and Capacity: Discussion paper No 58C, The European Centre for Development Policy Management: Maastrict, The Netherlands.

Varlas, L. (2007). Retirement Redefined. Education Update. 49(10), 1-2, 5 and 7-8.

Zachary, L. (2000). The Mentor's Guide: Facilitating Effective Learning Relationships. San Francisco: Jossey-Bass.

Zachary, L. (2005). Creating a Mentoring Culture: The Organization's Guide. San Francisco: Jossey-Bass.

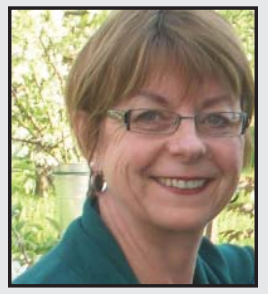

Julie Hobbs recently retired from Riverside School Board near Montreal as Assistant Director General. During her 34 years at Riverside and its predecessor board, she also served as a teacher, school administrator, education consultant, and Director of Educational Services. She has represented the English educational community at the provincial level in policy development and provincial-level reviews for curriculum and special education. She is currently working as a consultant in education, particularly in the area of special needs, as well as continuing to support "education through the arts" through the ArtsSmarts initiative at Riverside.

LINK TO:

www.rsb.qc.ca

www.artssmarts.ca 